\title{
Adapting land restoration to a changing climate
}

\section{Embracing the knowns and unknowns}

Emilia Pramova', Bruno Locatelli',2, Houria Djoudi³, Sandra Lavorel ${ }^{4}$, Matthew Colloff5, and Christopher Martius ${ }^{6}$

\section{Key messages}

- Land restoration will happen under climate change and different knowledge systems are needed to navigate uncertainties and plan adaptation.

- The emergence of novel ecosystems presents a challenge for land restoration; they harbor unknown unknowns.

- This brief presents key research linking land restoration and societal adaptation and an example of a practical framework for transformative adaptation.

- It also proposes questions that can guide stakeholders in exploring different change narratives for adaptation and restoration planning.

"Many of the human tragedies that we witness around the world, the floods, mudslides, droughts and famines, are not inevitable," John D. Liu tells us in his film, Hope in a Changing Climate. The film, first screened in 2009, features the restoration of the Loess Plateau in China and the subsequent dramatic improvement in the lives of local communities. The film demonstrates how reducing poverty, improving lives and sequestering carbon can be achieved simultaneously through natural solutions such as land restoration. But land restoration is also an important strategy for adaptation.

Even if bold efforts to curb climate change materialize, people will still need to adapt to the changes that have already happened, and these are projected to intensify in the future. And land restoration should be envisioned

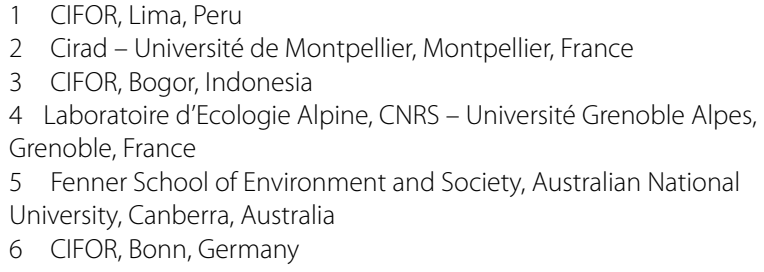

in this context; one of change and unpredictability, and the need to adapt. In this brief, we discuss the knowns and unknowns about land restoration and societal adaptation under climate change (Table 1). We include a list of questions that can help navigate the knowns and unknowns related to land restoration and people's adaptation in particular contexts.

\section{Land restoration and societal adaptation under climate change}

Conservative estimates show that about a quarter of the world's land is degraded, affecting at least 3.2 billion people (Scholes et al. 2018). The consequences are grave; for biodiversity and ecosystems, and for human livelihoods and well-being. Land degradation also represents a major constraint on attempts to achieve climate change mitigation, adaptation and sustainable development, while climate change will immensely exacerbate the impacts of land degradation.

The global community has responded to this challenge with initiatives and platforms that aim to facilitate land 
Table 1. The knowns-unknowns schema (Žižek 2006)

\begin{tabular}{|c|c|}
\hline Known Knowns & Unknown Knowns \\
\hline $\begin{array}{l}\text { What people know that they know; things they are aware of } \\
\text { and understand. Can be facts or beliefs. }\end{array}$ & $\begin{array}{l}\text { What people don't know that they know. Things they } \\
\text { understand but are not aware of. Value judgments and } \\
\text { implicit assumptions. }\end{array}$ \\
\hline Known Unknowns & Unknown Unknowns \\
\hline $\begin{array}{l}\text { What people know that they don't know. Things they are } \\
\text { aware of but don't understand. Accepted knowledge gaps } \\
\text { waiting to be solved. }\end{array}$ & $\begin{array}{l}\text { What people don't know that they don't know. Things they } \\
\text { are completely ignorant of and cannot foresee. Uncertainty } \\
\text { about the future. }\end{array}$ \\
\hline
\end{tabular}

restoration. One example is the Bonn Challenge, a global effort to restore 150 million ha of degraded and deforested land by 2020 and 350 million ha by 2030 . However, there is a limited understanding of the aims of land restoration under a changing climate.

Land restoration includes processes of ecological restoration, which, by definition, targets returning an ecosystem to conditions that have existed in the past, while recognizing that complete historical fidelity is impossible to achieve (Alexander et al. 2016). In reality, climate and other environmental changes will challenge objectives based on any degree of historical fidelity, even the less ambitious goals of recovery. For this reason, assisting a degraded ecosystem to enter a trajectory in which it can once again self-regenerate, re-organize and adapt might be a more pragmatic aspiration.

But restoration trajectories are also shaped by changing socioeconomic conditions and the decisions that societies make regarding the most desired ecosystem services, i.e. the contributions of ecosystems to human well-being. The values people hold, the rules that govern their behavior and the knowledge that they employ underpin these decision-making processes (Colloff et al. 2017), which become even more complex when different spatial and temporal scales are considered (e.g. at the landscape scale and under different climate scenarios).

The ecosystem services framework can provide helpful guidance for planning and implementing ecological restoration through its practical approaches and tools (Alexander et al. 2016), especially for assessing supply and trade-offs at larger spatial scales (Fedele et al. 2018). It is also the basis of ecosystem-based adaptation, which is realized when people base their adaptation strategies on ecosystem services such as water regulation by forests, storm protection by mangroves and provision of goods by trees (Pramova et al. 2012), to name a few.
As the field of ecological restoration shifts focus from reconstructing pre-disturbance conditions to restoring ecosystem services and adapting to future change (Harris et al. 2006), the issue of societal adaptation should also become prominent. The interactions between ecological and human factors in land restoration and societal adaptation are strong; they influence their respective trajectories and sustainability. For example, people's responses to climate variability and extremes affect ecosystems and the supply of ecosystem services, which, in turn, further influences the adaptive capacities of people and ecosystems (Djoudi et al. 2011).

In other words, the vulnerabilities of people and ecosystems are inseparable. It thus makes sense to approach land restoration through an integrated social-ecological adaptation perspective. Such a perspective can also be useful for managing ecological restoration under uncertainty, as we discuss later in this brief.

\section{The knowns}

Different fields of scientific inquiry have produced knowledge that is relevant for land restoration and adaptation to climate change, for example, research on the vulnerability of different species to climate change, the effects of restoration on ecosystem services and ecosystem resilience, and the role of ecosystem services in reducing societal vulnerability (Pramova et al. 2012).

Communities across the globe harbor local and traditional knowledge about environmental change and restoration that is significant (Rathwell et al. 2015). There are many examples of bottom-up approaches that consider existing practices and experiences, based on local knowledge systems of sustainable land management.

Case studies from Burkina Faso, Ethiopia, Ghana, Niger and Senegal reveal how smallholder-led practices are advancing and revising long-standing views and assumptions about restoration. To improve water availability and soil fertility, 
farmers, with or without external support, ingeniously modified traditional agroforestry, water and soil-

management practices by combining assisted regeneration, "zaï" techniques and other locally adapted practices.

Substantial economic, social and environmental benefits, including increases in crop yields, tree regeneration and soil conservation are well documented in different areas, eliciting broader regreening trends beyond the impact spheres of specific interventions (Stith et al. 2016).

This knowledge is vast and we do not attempt to cover it here. Under the known knowns, we outline the main messages from a literature review of research on land restoration and societal adaptation to climate change. We searched the SCOPUS database in September 2018 for papers about land restoration and adaptation to climate change that included 'restoration' in the title only and terms relating to ecosystems, climate and adaptation in the abstract, title or keywords. We may have omitted relevant papers, but our objective was an overview of key issues in restoration linked to adaptation rather than a systematic review. We found 175 papers, with only seven explaining a direct link between land restoration and societal adaptation.

Below we present three main messages from these seven papers, focusing on important issues for research and implementation.

The first message illustrates how land restoration can combine adaptation objectives with other goals such as livelihoods and community capacity building. Land restoration can reduce future risks (e.g. by protecting against hazards) and current vulnerability (e.g. by diversifying livelihoods). A cost-benefit analysis of mangrove restoration in Vietnam revealed economic benefits from timber harvesting, fishing and honey collection that accrued within the first few years following restoration, in addition to the avoided maintenance costs for coastal protection infrastructure in the longer term (Tri et al. 1998).

A study in South Africa showed how a restoration project diversified livelihoods and reduced overgrazing. This was done by growing lavender and rosemary for essential oils (Favretto et al. 2018). The NGO managing the project built a distillery to support production and delegated control to the farmers, thus providing an enhanced sense of ownership and empowerment which motivated long-term planning and actions.

In these examples, new knowledge creates benefits for multiple stakeholders: mangrove restoration in Vietnam is desirable because it provides clear economic benefits

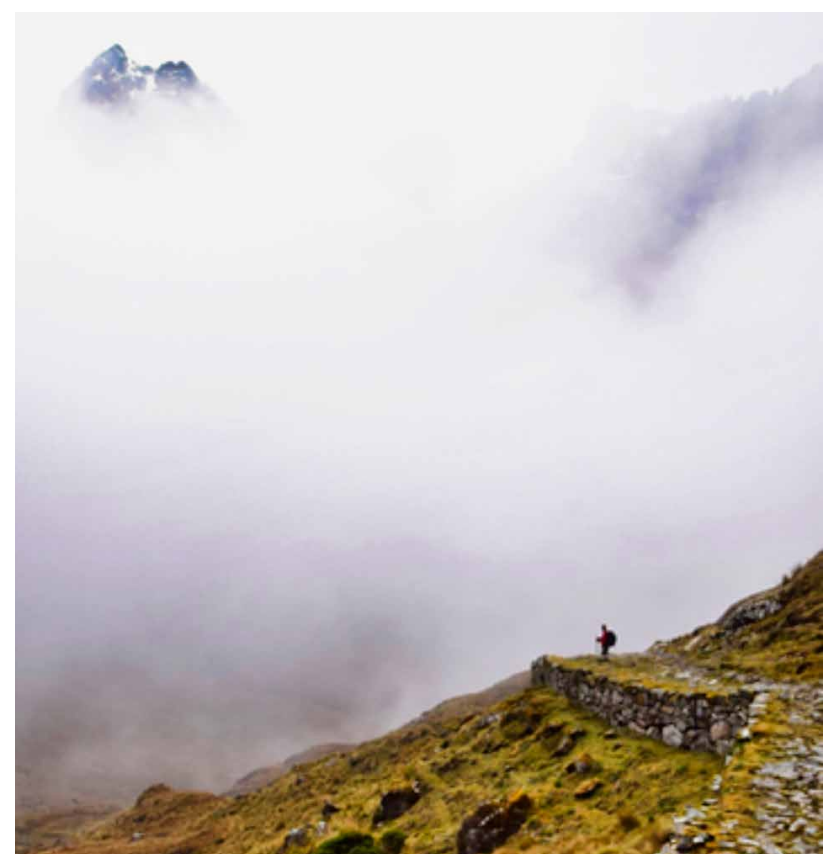

Adaptation to climate change requires navigating pathways toward unknown futures (photograph: trail in the Vilcabamba mountain range in the Peruvian Andes, by Bruno Locatelli)

to local communities and protects a larger group of stakeholders. Identification of such synergies can help in the design and implementation of restoration and adaptation objectives, even where there are significant uncertainties about future risks from environmental change. Overcoming sectoral boundaries and integrating different disciplines in research and implementation is key for achieving synergies.

A second message emphasizes the need for novel governance approaches. The development of governance and policy frameworks that integrate stakeholder views and priorities is an important consideration for successful Forest Landscape Restoration (FLR) (Reinecke and Blum 2018). This is particularly so when combining rural development with the restoration of multiple ecosystem services. New approaches require new governance arrangements that can take account of how different actors interpret and implement restoration, especially in local and bottomup initiatives, and of their motivations and expectations. Creating an environment for safe, active and inclusive participation is the first step in this direction.

There are similar governance concerns over the implementation of restoration and adaptation, including the power of governments to make decisions about land 


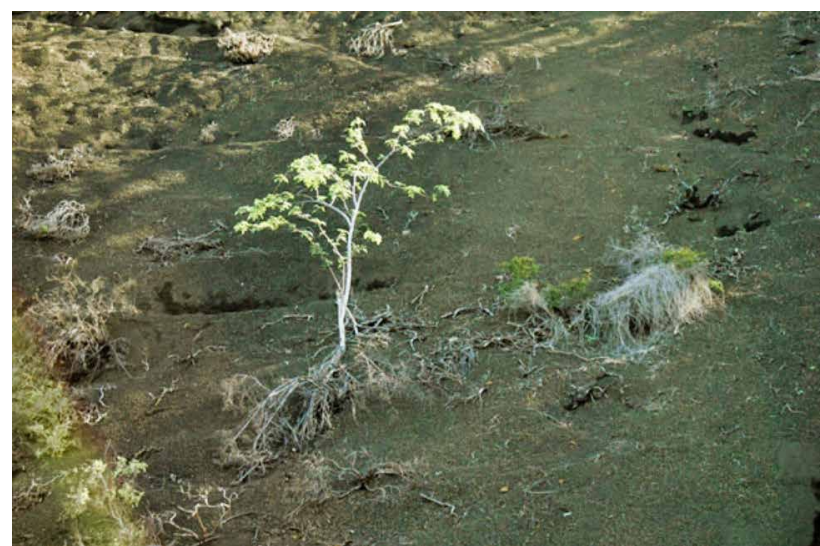

Restoration and adaptation strategies will increasingly come across novel ecosystems that enclose unknowns of their own (photograph: tree in the Galapagos Islands in Ecuador, by Bruno Locatelli)

uses according to political and economic considerations and vested interests without considering local communities. However, governments and legislatures are the major agents that can incentivize land rights, tenure and access through policy reforms and legislation. Major challenges remain about how to balance top-down with bottom-up governance and how to resolve issues of tenure and access.

Integration and coordination of policy and governance arrangements among government agencies can enhance the prospects of successful implementation and collaboration. In the South African case study above, job creation was a major objective of the "Working for Water" Initiative (Favretto et al. 2018) and labor-intensive restoration work was the policy means to achieve this end. But the narrow focus on job creation meant that the opportunity was missed for government agencies to work together to overcome community constraints to adaptation and achieve synergies from adaptation, mitigation and community development.

The third message that we identified is centered on the importance of considering the spatial configuration of land uses for managing trade-offs and synergies among ecosystem services. This was a critical issue in a case study of riparian forest restoration for flood management in the UK, as reduced flood risk at a particular floodplain segment may be achieved at the expense of catchment-scale benefits (Dixon et al. 2016). By using a spatial model of how different scenarios of restoration and forest growth affected the hydrology of the catchment, the most promising restoration scenarios for reducing flood risk management were identified at the sub-catchment scale.
A spatially explicit study in Hawaii modeled management costs and benefits from removing introduced grass- and shrubland and converting it to native forest. The model showed that restoration would contribute differently to reducing fire risk and increasing groundwater yield, depending on climate scenarios and the elevation of restored ecosystems (Wada et al. 2017). For example, under climate change, the greatest benefits would come from restoration at high elevations.

This new knowledge reveals the need for flexible and adaptive management under climate change. The authors proposed to start with restoration of high-elevation exclosures in low-cost areas and to gradually extend restoration downslope as the cost-effectiveness of fire reduction shifts to higher elevations under a drying climate (Wada et al. 2017).

\section{The unknowns}

Most of the scientific practice concentrates on testing hypotheses - the known unknowns. Usually, scientists expect results to be within a range of known possibilities, but frequently the results are counterintuitive. These are unknown unknowns uncovered, which then lead to more known unknowns. Incorporating traditional or indigenous knowledge systems can create novel hypotheses that challenge this dominant framing of western science (Rathwell et al. 2015).

There is a broader category of known unknowns related to land restoration and adaptation. In the Anthropocene, the current geological age in which humans are significantly altering the biophysical conditions of the planet, novel ecosystems are emerging. These ecosystems have unknown functional characteristics and may be difficult or impossible to restore to previous conditions (Harris et al. 2006). Novel ecosystems are no-analog systems, or systems that are ecologically distinct from historical analogs, containing new assemblies of biotic and abiotic components. They harbor unknown unknowns as well, and new approaches are needed to understand them and the associated emerging socioecological relationships.

Society normally recognizes the known unknowns, communicated by scientists and politicians, but chooses to remain oblivious to the unknowns. The philosopher Slavoj Žižek (2006) defined the unknown knowns as the silent presuppositions and disavowed beliefs that form the background of people's values and behavior. The goal of philosophical reflection, he noted, is precisely to discern the unknown knowns of our existence - the process of creation 
of meaning that people may be unaware of, but which is always present, structuring their approach to reality.

Sometimes, what is perceived as an unknown unknown might in fact be an unknown known. Something might be thought of as unpredictable and inconceivable when in fact relevant knowledge exists, for example about possible future changes in ecosystems and societal vulnerabilities. Similarly, uncertainties can also result from knowns that are obscured, either intentionally or unknowingly.

Even though unknowns and uncertainties have always been an integral part of human life, these terms have become strongly associated with climate change. Several frameworks and concepts can be useful for tackling unknowns and uncertainties in restoration and adaptation. Below we present some examples.

\section{Embracing all knowns and unknowns}

Mark Pelling (2011) defines adaptation as a continuum: from adaptation as resilience to adaptation as transition to adaptation as transformation. Adaptation as resilience preserves existing functions and practices under climate change while adaptation as transformation reforms political and economic regimes and related discourses on environment, development and risk in response to major environmental change. Adaptation as transition is intermediary: it aims at moving beyond persistence of the existing social-ecological system to achieve incremental adaptation in governance but without changing the dominant political-cultural regime.

A transformative adaptation pathway approach can embrace knowns and unknowns for navigating change. The framework of the Transformative Adaptation Research Alliance (TARA) describes three elements that can facilitate transformative adaptation: the adaptation pathways approach, the values, rules and knowledge perspective (VRK), and the adaptation services concept (Colloff et al. 2017).

Adaptation pathways are representations of uncertain futures that are similar to scenarios but that require a progressive process of addressing issues along the way such as: are decisions and actions robust to future scenarios and can they be stopped or reversed if conditions change? Will actions prevent the crossing of a biophysical threshold? The approach enables adaptive management through experimenting, co-learning and co-creating innovative options.
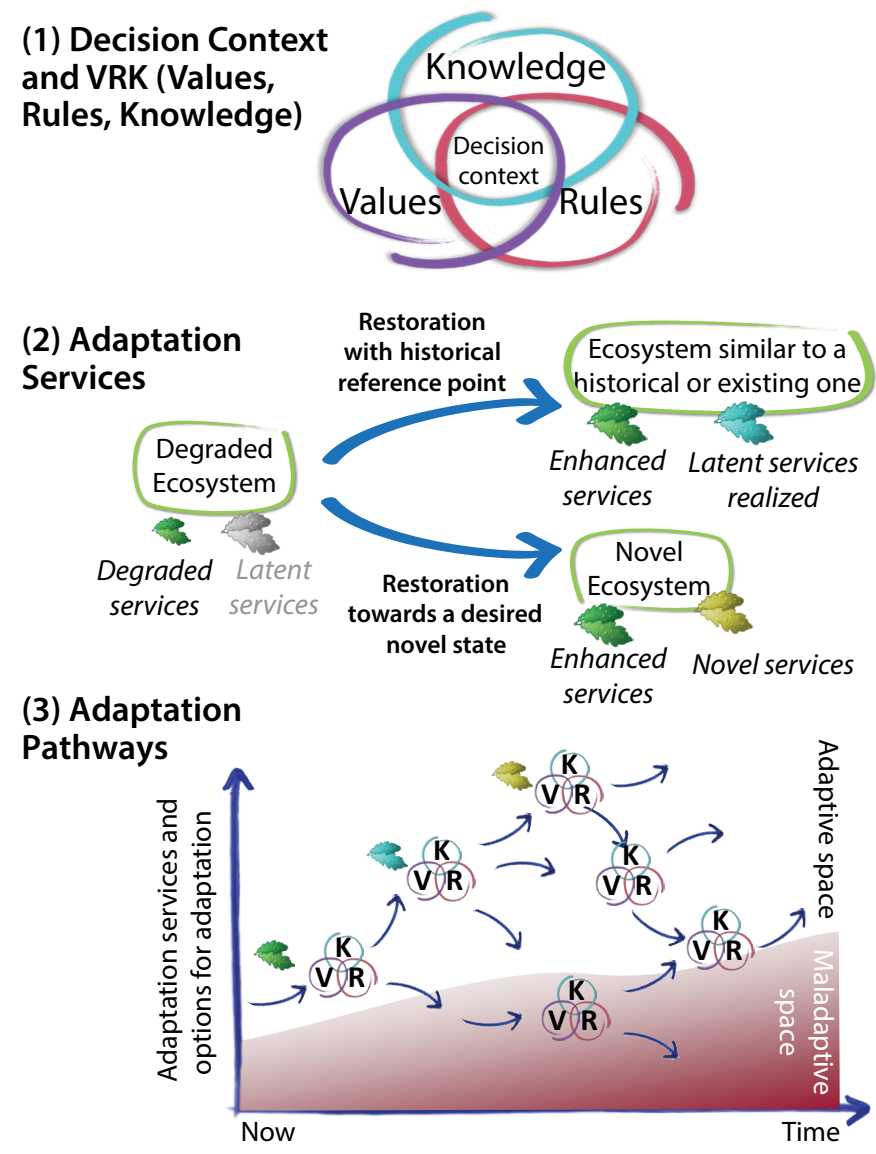

Figure 1. The three elements of the TARA approach (from Colloff et al. 2017) applied to restoration and adaptation: (1) Decision context, resulting from interactions between Values (what restoration outcome do we want?), Rules (are we allowed the outcome?) and Knowledge (do we know the outcome?); (2) Adaptation Services (benefits provided by ecosystems to help people adapt to environmental change, including ecosystem services from restored or novel ecosystems); and (3) Adaptation Pathways (representations of uncertain futures with possible shifts in the decision context and adaptation services)

The VRK perspective considers the interactions between systems of societal values and rules, and the forms of knowledge legitimized by decision makers, and how these interactions shape the decision contexts within which adaptation is planned and implemented. It helps to identify how decision making is constrained by the preferences of certain stakeholders and their institutional context and world views. 
Values pluralism, or the multiple ways of understanding nature, is inherent to the VRK perspective. Including values pluralism in deliberating and making decisions creates space for novel adaptation approaches. Openness to different knowledge systems and world views helps agents to imagine futures that are radically different from the present and to prepare for navigating change.

As the VRK perspective examines and reframes decision contexts at each point in the adaptation pathway, participants can achieve more power and agency by engaging in questioning, learning and reforming the institutional framework in which adaptation occurs.

Finally, the concept of adaptation services adjusts the ecosystem services framework in relation to global change. Adaptation services are the benefits provided by ecosystems to help people adapt to environmental change. They are realized through co-production of visions for future landscapes and livelihoods, based on what is known about likely trajectories of ecosystem change and by building in contingencies for uncertainties (Lavorel et al. 2019). The concept is relevant for ecological restoration as it can reveal novel benefits to people from the capacity of ecosystems to transform and supply new services. It focuses on anticipating possible climate change impacts and mobilizing knowledge, and social and material capital, for the realization of adaptation service benefits.

Approaching land restoration through a transformative adaptation pathway is an opportunity not only to address degradation, climate change and all associated uncertainties but also to question the dominant narratives in development and (unsustainable) relationships between people and environment.

\section{Knowledge systems and power}

Knowledge systems are integral to environmental governance and navigating environmental change. But they cannot be contemplated independently of power (Tengö et al. 2014). The power of dominant groups is reflected in the dominant knowledge systems and their narratives about the environment.

Scientific knowledge usually prevails in making sense of, and deciding about, environmental change. Although discrete categories such as 'scientific knowledge' and 'indigenous knowledge' are a simplification, neglecting the differences and similarities among knowledge systems and their associated world views can perpetuate power asymmetries in environmental governance (Rathwell et al. 2015).
In this regard, major international organizations are now making efforts to engage with other knowledge systems. The Intergovernmental Science-Policy Platform on Biodiversity and Ecosystem Services (IPBES), for example, is reframing the concept of 'ecosystem services' (linked to the instrumental value systems of western societies) by using the term 'nature's contributions to people' (linked to the relational value systems of many indigenous communities) (Scholes et al. 2018).

The deep place-based narratives that local communities maintain about past and present environmental change are essential for envisioning future ecosystems and how they might evolve under different scenarios. When the ecosystem of Lake Faguibine in Mali transitioned from a lake to a forest, the local narratives revealed a shifting distribution of vulnerabilities within livelihoods and groups, but also new coping strategies and potential for adaptation (Djoudi et al. 2011).

Even though forests played an integral part in the response strategies of different groups, various factors undermined the sustainable use of forest resources and created new patterns of dependency. Local decision makers and NGOs aspiring to "bring back the lake" were largely unaware of this new role of the forest and the changes in vulnerability across and within groups.

Local community narratives will frequently challenge the dominant ones about change (Rathwell et al. 2015). A meta-analysis of restoration ecology papers revealed that restoration scientists and practitioners were failing to adequately link the ecological benefits of restoration to societal well-being (Aronson et al. 2010). Thus, the dominant restoration narratives are in danger of remaining primarily environmental, and this has important implications for policy and funding.

We present a list of questions that can be useful for the synthesis of local narratives related to land restoration and adaptation, as well as for scenario building with the stakeholders concerned (Box 1). With these questions, we do not intend for an interventionist framing of restoration and adaptation, but rather to inspire critical exchanges about these concepts and more integrative research and implementation that go beyond disciplinary boundaries. Ultimately, the question that always needs to be asked first is: what are the existing local and traditional best practices in restoration and adaptation and how can we help to scale them up? 


\section{Box 1: Examples of questions that can guide stakeholders in exploring narratives of different knowledge systems, and in co-producing restoration and adaptation scenarios.}

\section{Narratives of past and current change}

- What are the most important socioeconomic and ecological changes that have occurred in the landscape in the past?

- How are the different ecosystems in the current landscape governed? What are the different perceptions of ecosystem governance?

- What are the existing ecosystem services and adaptation services? Both the identified and valued but also potential services of current ecosystems that have not been identified and valued.

- Who benefits from the services? Who is excluded?

- What kind of coping and adapting strategies occur in the landscape?

\section{Co-production of climate and restoration scenarios}

- Is restoration to past states feasible and desirable? Are novel ecosystems appearing or are they likely to arise in the future?

- What is the general aim with ecological restoration in the landscape: enhancing core ecosystem functions, maintaining evolutionary potential, enhancing biodiversity, managing for particular ecosystem services?

- What is the reference ecosystem - is it a hypothetical one? An existing one? How do the socioecological characteristics (existing or envisioned) compare to the characteristics of the current ecosystems and landscape?

- What restoration and adaptation pathways can be defined collectively? Are diverse values and knowledge included in defining them?

- How might different restoration and adaptation pathways affect existing ecosystem services, adaptation services, the people that depend on them or value them, and the existing coping and adapting strategies?

- Where and when might trade-offs between ecosystem services occur? How might they affect adaptation services and adaptation pathways?

- Based on what values and prioritization are the desired restoration and adaptation pathways defined collectively?

- To what extent does a restoration and adaptation pathway lead to dependency (inability to change path or course of action)?

- How is the restoration process likely to be governed? How will this affect the adaptive capacity of different groups and ecosystems? What are the governance scenarios for the restored ecosystems in the landscape?

- During the restoration process, and when land becomes restored, how might power relationships evolve? What kind of institutions can be developed and supported to monitor and mitigate power asymmetries?

- How can social learning be supported during and after the restoration process?

- Are there mechanisms in place to anticipate and manage trade-offs? If not, what can be done?

\section{Acknowledgments}

The funding partners that have supported this research include the International Climate Initiative (IKI) of the German Federal Ministry for the Environment (BMUB), the Norwegian Agency for Development Cooperation (NORAD) and the CGIAR Research Program on Forests, Trees and Agroforestry (CRP-FTA) with financial support from the CGIAR Fund.

\section{References}

Alexander S, Aronson J, Whaley O and Lamb D. 2016. The relationship between ecological restoration and the ecosystem services concept. Ecology and Society 21(1).
Aronson J, Blignaut JN, Milton SJ, Maitre DL, Esler KJ, Limouzin A, Fontaine C, Wit MPD, Mugido W, Prinsloo P, Elst LVD and Lederer N. 2010. Are socioeconomic benefits of restoration adequately quantified? A meta-analysis of recent papers (2000-2008) in Restoration Ecology and 12 other scientific journals. Restoration Ecology 18(2):143-54.

Colloff MJ, Martín-López B, Lavorel S, Locatelli B, Gorddard R, Longaretti PY, Walters G, Kerkhoff LV, Wyborn C, Coreau A, et al. 2017. An integrative research framework for enabling transformative adaptation. Environmental Science \& Policy 68:87-96.

Dixon SJ, Sear DA, Odoni NA, Sykes T and Lane SN. 2016. The effects of river restoration on catchment scale flood risk and flood hydrology. Earth Surface Processes and Landforms 41(7):997-1008. 
Djoudi H, Brockhaus M and Locatelli B. 2011. Once there was a lake: Vulnerability to environmental changes in northern Mali. Regional Environmental Change 13(3):493-508.

Favretto N, Dougill A, Stringer L, Afionis S and Quinn C. 2018. Links between climate change mitigation, adaptation and development in land policy and ecosystem restoration projects: Lessons from South Africa. Sustainability 10(3):779

Fedele G, Locatelli B, Djoudi H and Colloff MJ. 2018. Reducing risks by transforming landscapes: Cross-scale effects of land-use changes on ecosystem services. Plos One 13(4).

Harris JA, Hobbs RJ, Higgs E and Aronson J. 2006. Ecological restoration and global climate change. Restoration Ecology 14(2):170-76.

Lavorel S, Colloff MJ, Locatelli B, Gorddard R, Prober SM, Gabillet M, Devaux C, Laforgue D and Peyrache-Gadeau V. 2019. Mustering the power of ecosystems for adaptation to climate change. Environmental Science \& Policy 92:87-97.

Pelling M. 2011. Adaptation to Climate Change: From Resilience to Transformation. Abingdon, Oxon, England: Routledge.

Pramova E, Locatelli B, Djoudi H and Somorin OA. 2012. Forests and trees for social adaptation to climate variability and change. Wiley Interdisciplinary Reviews: Climate Change 3(6):581-96.

Rathwell KJ, Armitage D and Berkes F. 2015. Bridging

knowledge systems to enhance governance

of environmental commons: A typology of

settings. International Journal of the Commons 9(2):851-80.
Reinecke S and Blum M. 2018. Discourses across scales on forest landscape restoration. Sustainability 10(3):613.

Scholes R, Montanarella L, Brainich A, Barger N, ten Brink B, Cantele M, Erasmus B, Fisher J, Gardner T, Holland T, et al., eds. 2018. Summary for Policymakers of the Assessment Report on Land Degradation and Restoration of the Intergovernmental Science-Policy Platform on Biodiversity and Ecosystem Services. Bonn, Germany: IPBES secretariat.

Stith M, Giannini A, Corral JD, Adamo S and Sherbinin AD. 2016. A quantitative evaluation of the multiple narratives of the recent sahelian regreening. Weather, Climate, and Society 8(1):67-83.

Tengö M, Brondizio ES, Elmqvist T, Malmer P and Spierenburg M. 2014. Connecting diverse knowledge systems for enhanced ecosystem governance: The multiple evidence base approach. Ambio 43(5):579-591.

Tri NH, Adger NW and Kelly MP. 1998. Natural resource management in mitigating climate impacts: The example of mangrove restoration in Vietnam. Global Environmental Change 8(1):49-61.

Wada CA, Bremer LL, Burnett K, Trauernicht C, Giambelluca T, Mandle L, Parsons E, Weil C, Kurashima N and Ticktin T. 2017. Estimating cost-effectiveness of Hawaiian dry forest restoration using spatial changes in water yield and landscape flammability under climate change. Pacific Science 71(4):401-424.

Žižek S. 2006. Philosophy, the "unknown knowns," and the public use of reason. Topoi 25(1-2):137-42.
RESEARCH PROGRAM ON

Forests, Trees and Agroforestry
The CGIAR Research Program on Forests, Trees and Agroforestry (FTA) is the world's largest research for development program to enhance the role of forests, trees and agroforestry in sustainable development and food security and to address climate change. CIFOR leads FTA in partnership with Bioversity International, CATIE, CIRAD, ICRAF, INBAR and TBI.

FTA's research is supported by CGIAR Fund Donors: cgiar.org/funders/ 